\title{
Validation of the Numerical Anxiety Rating Scale in postpartum females: a prospective observational study
}

\author{
Anna Prokopowicz ${ }^{1}$, Bartlomiej Stanczykiewicz ${ }^{2}$ (D) Izabella Uchmanowicz ${ }^{3}$ (1) \\ ${ }^{1}$ Division of Midwifery and Gynaecological Nursing, Department of Nursing and Obstetrics, Faculty of Health Sciences, \\ Wroclaw Medical University, Wroclaw, Poland \\ ${ }^{2}$ Division of Consultation Psychiatry and Neuroscience, Department of Psychiatry, Faculty of Medicine, \\ Wroclaw Medical University, Wroclaw, Poland \\ ${ }^{3}$ Division of Internal Medicine Nursing, Department of Nursing and Obstetrics, Faculty of Health Sciences, \\ Wroclaw Medical University, Wroclaw, Poland
}

\begin{abstract}
Objectives: Perinatal anxiety is important for the quality of life of mothers and their offspring. The Numerical Anxiety Rating Scale (NRS-A) allows the level of anxiety in patients to be quickly assessed. Until now, the NRS-A has not been validated in the postpartum female population. The aim of this study was to assess the accuracy and reliability of the NRS-A when compared with the reference methods for measuring anxiety.

Material and methods: The observational prospective study included a group of 200 adult postpartum females of a hospital maternity ward. The validity between the Numerical Rating Scale for Anxiety (NRS-A) and the State and Trait Anxiety Inventory (STAI), and between the NRS-A and the Hospital Anxiety and Depression Scale (HADS-A), was determined. The detection thresholds for high anxiety were examined.

Results: Both measurements showed a positive high correlation between the NRS and STAI-S (in T1 rho $=0.807$, in T2 rho $=0.778 ; p<0.001$ ), and a comparable relationship of both scales (STAI-S and NRS-A) with the STAI-T and HADS-A. The analysis of the ROC curve indicated that the value of the NRS-A equal to $3.5 / 10$ can be considered the threshold that allows for a differentiation of patients with high anxiety from those without high anxiety in the studied population.

Conclusions: The NRS-A is an accurate tool for measuring anxiety in Polish postpartum females. Routine anxiety measurements using the NRS-A can be used to identify people with high anxiety in order to provide emotional support to patients in the early postpartum period.
\end{abstract}

Key words: anxiety; postpartum period; patient-oriented outcomes; emotional support

Ginekologia Polska 2022; 93, 9: 686-694

\section{INTRODUCTION}

The perinatal symptoms of anxiety and mood are common and important for the long-term and short-term quality of life of mothers and their offspring. High perinatal anxiety can lead to anxiety and affective disorders. In the postpartum period, women experience generalized anxiety disorder and panic attacks. In addition, obsessive-compulsive disorder, as well as acute and post-traumatic stress disorder symptoms may occur [1-4].

In populations of women evaluated in the perinatal period, anxiety and depressive disorders coexist [5, 6]. In the group of women diagnosed with postpartum depression, anxiety disorders were also found in $82.9 \%$ of them, and vice versa - in women with primary anxiety disorders, coexisting depressive disorders were found [7]. Some evidence shows that the incidence rate of perinatal anxiety is about $22 \%$, which is higher than the incidence rate of perinatal depression (13\%) [8].

Conclusions from studies conducted on populations of women in the perinatal period include recommendations for high-quality prenatal care systems regarding the routine control of anxiety and mood levels in this period $[9,10]$. The Polish standard of perinatal care only recommends examining the perinatal risk of depression [11]. Moreover, it is standard in hospital care that patients are informed about their right to pain treatment. However, there 
are no such recommendations for anxiety, even though studies show that pain coexists with anxiety [12-14].

The study of anxiety among women in the postpartum period may not only be important for the selection of anxiety and depressive disorders in perinatal patients, but above all for the description and normalization of anxiety emotions in this population. According to the authors of Acceptance and Commitment Therapy, anxiety, as well as pain, loss, regret and disappointment, are inseparable elements of human life [15]. However, in order to discuss maternal anxiety in the postpartum period on the basis of scientific evidence, maternity staff should have a simple and relevant tool to measure it. A study by the Silverwood team (2019) [16] shows that there is insufficient understanding of what perinatal anxiety is among healthcare professionals. Employees declare that they lack knowledge concerning "normal perinatal anxiety", as well as simple tools for its screening. In turn, patients with perinatal anxiety declare that they do not receive sufficient support. The recommendations of the National Institute for Health and Care Excellence (NICE) include a provision concerning the recommendation of the assessment of the support needed by women with mental health problems, as well as the women at risk of developing them [17].

Commonly used scales to assess anxiety levels include descriptive scales, such as: Hospital Anxiety and Depression Scale (HADS) for measuring anxiety (A) and depression (D), Beck Anxiety Inventory, and State-Trait Anxiety Inventory (STAI) for measuring two separate anxiety concepts: state anxiety $(\mathrm{S})$ and trait anxiety $(\mathrm{T})[12,18]$. STAI-S, due to its high accuracy and reliability in various populations, is the recommended tool for measuring state anxiety [18, 19]. The results of testing the level of state anxiety are sensitive to the variability of anxiety, which depends on situations related to external stimuli [20]. The listed questionnaires contain multiple items. The filling in of them by postpartum females may be difficult due to the lack of time that is related to having to care for their newborns. In the case of limited time possibilities, it is reasonable to use quick measurement scales, e.g., a single 0 to 10 numerical rating scale (NRS), which is commonly used to measure pain. Despite its simplicity, its validity and reliability have also been demonstrated [21]. The twin NRS for anxiety (NRS-A) has been tested in the dental and pediatric patient population $[22,23]$. Until now, the NRS-A has not been validated in the postpartum female population.

Therefore, the aim of this study is to answer the question of whether NRS-A is a valid and reliable measurement tool for assessing state anxiety in postpartum women in the first days of puerperium when compared to the reference STAI-S method. An additional goal is to test the detection threshold of high anxiety using the NRS-A, as well as to compare the anxiety of patients in two independent groups: those declaring a need for emotional support versus those declaring no need for emotional support.

\section{MATERIAL AND METHODS \\ Population and settings}

The place of study was the maternity ward in the $2^{\text {nd }}$ Department of Gynaecology and Obstetrics of the Wroclaw Medical University, Poland. 200 women during their first and second postpartum days were included in the study. The data was collected in the period from 27/12/2020 to $04 / 30 / 2021$. Adult patients, who gave conscious consent to the study and who gave birth at term (i.e., $\geq 37 \mathrm{hbd}$ ) to a single newborn in good condition (from 8-10 Apgar points), both by caesarean section and naturally, were enrolled in the research. The condition for inclusion in the study was also the good condition of the mother after childbirth (patient mobilized, with physiological blood loss during childbirth, no blood transfusion, qualified to "rooming" (maternity ward) with their newborn, and with no diagnosed mental, psychological, or orthopaedic dysfunctions).

Data concerning the patient's postpartum condition, medical history, and the health of their newborn were obtained from the medical history of the patient and newborn. The study was confidential. Access to the collected data was secured, and each of the studied participants was given an identification number, which enabled the data to be anonymized.

\section{Tools}

Numerical Rating Scale for anxiety (NRS-A)

The raw anxiety scores on a numerical scale from 0 to 10 were categorized as: 0 - not anxious, $1-3$ - little/slightly anxious, 4-6 - medium/fairly anxious, 7-9 - a lot/very anxious, 10 - worst imaginable/extremely anxious [22, 23].

\section{State-Trait Anxiety Inventory (STAI)}

The STAI, which was developed from its original version, was adapted to the Polish population by the Spielberger team $[20,24]$. It consists of two separate scales, which both have 20 questions. The total continuous scores range from a minimum of 20 to a maximum of 80 . The higher the total score, the higher the level of state anxiety [at a given time on the $\mathrm{X}-1$ scale (STAI-S)] and trait anxiety [on the X-2 scale (STAI-T)]. The obtained results are interpreted on three levels: low anxiety (1-4 sten), moderate anxiety (5-6 sten) and high anxiety (7-10 sten). The cut-off point for high state anxiety starts above 40 [20]. Cronbach's alpha in our study was for state anxiety (STAI-S) tested on the first day (T1) -0.956 and second day (T2) -0.958 , and for trait anxiety it was (STAI-T) -0.850 .

\section{Hospital Anxiety and Depression Scale (HADS)}

The HADS questionnaire by Zigmond and Snaith (1983) [25] enables the level of anxiety and depression of patients 
Table 1. Individual measurements of the observed variables during the study, and the number of correctly completed questionnaires for a group of 200 postpartum females

\begin{tabular}{|l|c|c|c|}
\hline Variable & Questionnaire & Measurement T1 & Measurement T2 \\
\hline State anxiety & STAI-S-X1 & $X(n=200)$ & $X(n=200)$ \\
\hline Trait anxiety & STAI-T-X2 & $X(n=200)$ & - \\
\hline State anxiety & NRS-A & $X(n=200)$ & $X(n=187)$ \\
\hline Anxiety & HADS-A & - & $X(n=200)$ \\
\hline Need for emotional support & NES & $X(n=200)$ & \\
\hline
\end{tabular}

$X$ - presence of measurement; - - lack of measurement

in hospital conditions to be assessed. The Polish adaptation of the questionnaire was made by the Majkowicz team (2000).[26] Anxiety can be assessed using the independent subscale of the Hospital Anxiety and Depression Scale-Anxiety (HADS-A), which consists of seven questions. For each of them, 0 to 3 points (the maximum number of points is 21) can be achieved. The cut-off point for an anxiety disorder is a score greater than 10 points. Cronbach's alpha for HADS-A in the present study -0.829 .

\section{Need for Emotional Support (NES)}

The need for emotional support was tested using the question developed by authors: "In my current situation, I need emotional support."The answers were given on a 6-point Likert scale (1 — "I strongly disagree", 2 - "I disagree", 3 - "I disagree a little", 4 —-"I agree a little", 5 —-"I agree", and 6 - "I strongly agree"). Single-question scales that fit the specific clinical situation of patients are used in scientific publications [27]. For the purpose of selecting patients who declared a need for emotional support vs those that did not need support, answers from 1 to 3 were included in the group of patients who did not need emotional support, and answers from 4 to 6 were included in the group of patients who declared a need for emotional support.

\section{Bioethics committee}

A written informed consent to participate in the study was obtained from all the patients. The study was approved by the Bioethics Committee at Wroclaw Medical University, Wroclaw, Poland (KB No. 747/2020).

\section{The presentation of measurements at both timepoints}

After giving informed consent to participate in the study, the patients were asked to fill in questionnaires at two timepoints: on the first postpartum day (T1) and on the second postpartum day (T2). On both days, the patients completed NRS-A, STAI-S-X1 and NES. Additionally, on the first postpartum day (T1), they completed STAI-T-X2, and on the second day (T2) they completed HADS-A. The individual measurements over time are presented in Table 1. Incomplete, or blank questionnaires were considered as missing data. In T2, there were 13 deficiencies for anxiety measured using HADS-A.

\section{Statistical analysis}

The IBM SPSS Statistics 26 program (IBM Corp., Armonk, NY, USA) was used for statistical analysis. Due to the non-Gaussian distribution of all the variables, non-parametric tests were used for the analysis. The relationship between NRS-A, STAI and HADS-A is shown by Spearman's correlation coefficient (rho). The non-parametric Mann-Whitney $U$ test was used to compare independent groups, and the Wilcoxon test was used to compare dependent groups. NRS-A thresholds of differentiation with regards to anxiety or non-anxiety (defined by the reference STAI-S cut-off point equal to 40, and HADS equal to 10) were determined based on Receiver Operating Characteristic $(\mathrm{ROC})$ curves and their related area under the ROC curve (AUC). The significance of the measurements was assumed for the value of $p<0.05$.

The sample size, with an estimated mean effect size and an alpha error probability of 0.05 , was determined according to literature [23].

\section{Participants}

In the study, 200 women aged Mdn = 32 (range: $21-43$ ) took part. Most of the patients (83\%) declared higher education, a good financial situation (87.1\%) and living in a formal relationship (78\%). In the study group, $56 \%$ of patients gave birth to a child by caesarean section (Tab. 2).

\section{RESULTS}

The descriptive statistics for the tools used in the study are presented in Table 3. The Wilcoxon test showed no differences in the measurements between the first (T1) and the second (T2) day in the case of anxiety measured using STAI-S $(Z(199)=-0.658 ; p>0.5)$ and in the case of anxiety measured using NRS-A $(Z(199)=-1.928 ; p>0.5)$.

Correlations of comparable strength were shown between the dependent measurements ( $\mathrm{T} 1$ with $\mathrm{T} 2$ ). They 
were calculated separately for NRS-A ( $r$ o $=0.708 ; p<0.001)$ and for STAI-S (rho $=0.701 ; \mathrm{p}<0.001)$.

\section{Correlations between the NRS-A, STAI and HADS-A measurements}

The correlations between STAI-S and NRS-A were positive and high in both measurements $(p<0.001)$. They amounted to in $\mathrm{T} 1$ rho $=0.807$, in $\mathrm{T} 2$ rho $=0.778$. A graphical representation of the relationship between STAI-S and NRS-A for individual measurements is shown in Figure 1.

\begin{tabular}{|c|c|}
\hline Parameter & Total $(n=200)$ \\
\hline \multicolumn{2}{|l|}{ Age } \\
\hline 20-30 years old & $81(40.5 \%)$ \\
\hline $31-40$ years old & $113(56.5 \%)$ \\
\hline $41-50$ years old & $6(3 \%)$ \\
\hline \multicolumn{2}{|l|}{ Type of childbirth } \\
\hline Natural childbirth & $88(44 \%)$ \\
\hline Childbirth by caesarean section & $112(56 \%)$ \\
\hline \multicolumn{2}{|l|}{ Education } \\
\hline Higher & $166(83 \%)$ \\
\hline Secondary & $19(9.5 \%)$ \\
\hline Vocational & $11(5.5 \%)$ \\
\hline Lower secondary & $3(1.5 \%)$ \\
\hline Primary & $1(0.25 \%)$ \\
\hline \multicolumn{2}{|l|}{ Financial status } \\
\hline Good & $175(87.5 \%)$ \\
\hline Average & $23(11.5 \%)$ \\
\hline Poor & $2(1 \%)$ \\
\hline \multicolumn{2}{|l|}{ Marital status } \\
\hline Formal relationship & $156(78 \%)$ \\
\hline Informal relationship & $33(16.5 \%)$ \\
\hline Single & $11(5.5 \%)$ \\
\hline
\end{tabular}

The correlation between STAI-T and NRS-A, and STAI-T and STAI-S, as well as between HADS-A and NRS-A and HADS-A and STAI-S showed positive correlations of similar strength and significance $(p<0.001)$ for both scales (Tab. 4).

\section{Cut-off points on the NRS-A scale}

Analysis of the ROC curve for the 200 patients suggested a value of 3.5/10 on the NRS-A scale as the threshold for high anxiety (defined by the reference STAI-S cut-off of 40) in both measurements (in T1 AUC $=0.886 ; p<0.001$ and in T2 AUC $=0.860 ; p<0.001$ ). Both measurements showed acceptable values of sensitivity ( $\mathrm{T} 1-0.803$; $\mathrm{T} 2-0.702)$ and specificity (T1 - 0.843; T2 - 0.849) (Fig. 2).

The analysis of the ROC curve for 187 patients suggested a value of $4.5 / 10$ on the NRS-A scale for T1 and T2 (for STAI-S the value of $42.5 / 80$ in T1, and the value of $50.5 / 80$ in T2) as a threshold to indicate the risk of an anxiety disorder (defined by the HADS-A reference cut-off of 10). The model adjustment values on the first day (T1) for NRS-A were: $A U C=0.852 ; p<0.001$; sensitivity $=0.895$; and specificity $=0.678$; and for STAI-S they were: $\mathrm{AUC}=0.842$; $p<0.001$, sensitivity $=0.947$, and specificity $=0.617$. The model adjustment values on the second day (T2) were for NRS-A: $A \cup C=0.880 ; p<0.001$, sensitivity $=0.842$, and specificity $=0.792$; and for STAI-S: AUC $=0.863 ; \mathrm{p}<0.001$, sensitivity $=0.711$, and specificity $=0.846$ (Fig. 3).

\section{Levels of anxiety by the need for emotional support}

From the group of 200 patients, 101 (50.5\%) declared a need for emotional support on the first day (T1), and 96 (48.0\%) patients on the second day (T2). The Mann-Whitney $U$ test showed, in both the NRS-A and STAI-S scores, a higher $(p<0.001)$ level of anxiety in the group of women declaring a need for emotional support when compared to the group of women not declaring a need for emotional support (Tab. 6).

\begin{tabular}{|l|c|c|c|c|c|}
\hline \multicolumn{2}{|l}{ Table 3. Descriptive statistics for NRS-A, STAI, HADS-A, and NES in T1 and T2 } \\
\hline Questionnaire and the measurement (T) & $\mathbf{n}$ & Mdn & IQR & Min & Max \\
\hline NRS-A_T1 & 200 & 4 & 4 & 0 & 10 \\
\hline NRS-A_T2 & 200 & 3 & 3 & 0 & 10 \\
\hline STAI-S_T1 & 200 & 42.5 & 16 & 20 & 79 \\
\hline STAI-S_T2 & 200 & 42 & 17.75 & 20 & 77 \\
\hline STAI-T_T1 & 200 & 37 & 10 & 21 & 68 \\
\hline HADS-A_T2 & 187 & 7 & 6 & 0 & 20 \\
\hline NES_T1 & 200 & 4 & 3 & 1 & 6 \\
\hline NES_T2 & 200 & 3 & 3 & 1 & 6 \\
\hline
\end{tabular}

HADS-A — Hospital Anxiety and Depression Scale-Anxiety; IQR — interquartile range; Mdn — median; Min — minimum value; Max — maximum value; $\mathrm{n}$ — number of subjects; NES - need for emotional support; NRS-A — Numerical Rating Scale for Anxiety; STAI-S — State and Trait Anxiety Inventory-State Anxiety 


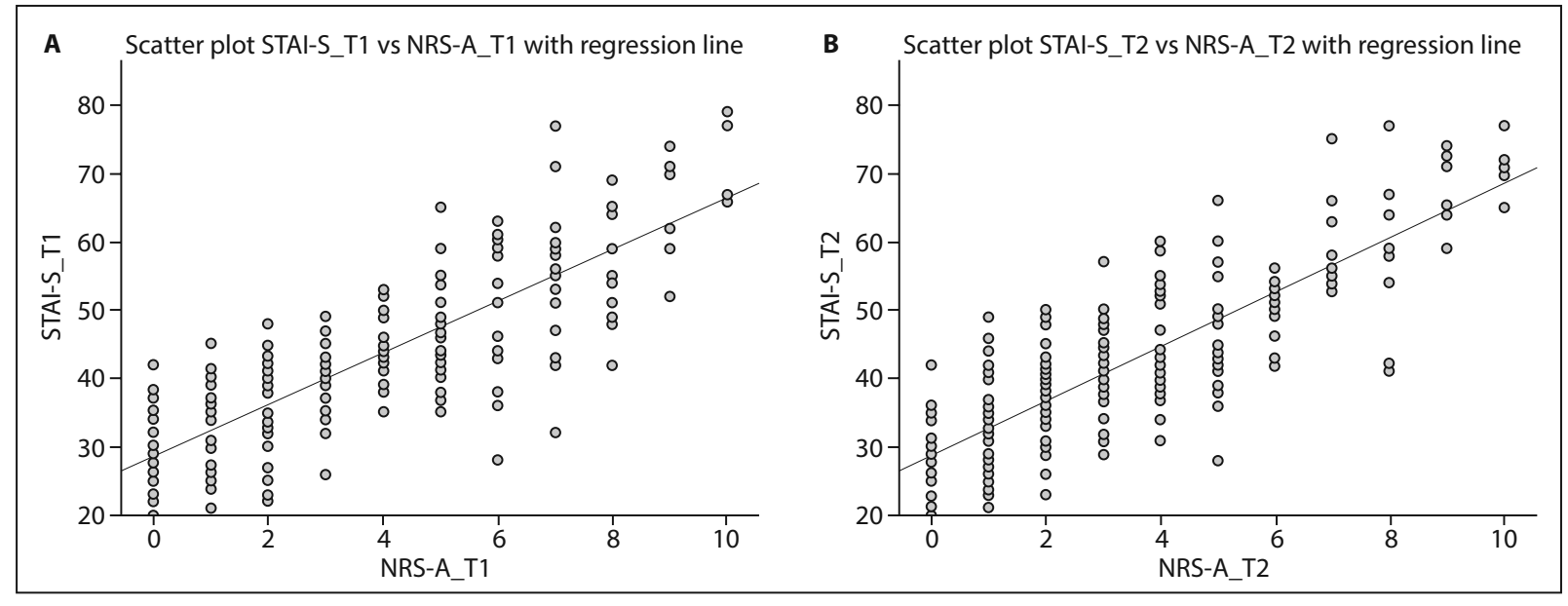

Figure 1. Scatter plots for correlations between STAI-S and NRS-A for both timepoints; $\mathbf{A}$. Scatter plot for STAI-S_T1 vs. NRS-A_T1 with a regression line $[Y=3.769( \pm 0.193) \cdot X+28.670( \pm 0.927) ; p<0.001 ; R 2=0.658] ; B$. Scatter plot for STAI-S_T2 vs NRS-A_T2 with a regression line [Y= 3.990 $( \pm 0.200) \cdot X+28.620( \pm 0.901) ; p<0.001 ; R 2=0.667]$

Table 4. Correlation between trait anxiety measured using STAI-T $(n=200)$ and HADS-A $(n=187)$ with state anxiety measured using NRS-A and STAI-S for the measurements at two timepoints

\begin{tabular}{|l|c|c|c|c|}
\hline \multirow{2}{*}{ Spearman's correlation coefficient } & \multicolumn{2}{|c|}{ T1 } & \multicolumn{2}{c|}{ T2 } \\
\cline { 2 - 5 } & NRS-A & STAI-S & NRS-A & STAI-S \\
\hline STAI-T_T1 & 0.336 & 0.387 & 0.354 & 0.406 \\
\hline p-value & 0.000 & 0.000 & 0.000 & 0.000 \\
\hline HADS-A_T2 & 0.716 & 0.733 & 0.686 & 0.691 \\
\hline p-value & 0.000 & 0.000 & 0.000 & 0.000 \\
\hline
\end{tabular}

HADS-A — Hospital Anxiety and Depression Scale-Anxiety; NRS-A — Numerical Rating Scale for Anxiety; STAI-S — State and Trait Anxiety Inventory-State Anxiety; STAI-T — State and Trait Anxiety Inventory-Trait Anxiety

\section{DISCUSSION}

Internal consistency of the results for state anxiety on the STAI-S scale in the present study, in both measurements (evaluated by Cronbach's alpha), was high (above 0.9) and comparable to the reliability of the STAI-S results for Polish women in the age range of 21-40 years (0.89) [20]. This value is comparable to Cronbach's alpha STAI-S value in scientific literature [28-30]. The high reliability of measurements using the STAI-S questionnaires in the study allows these tools to be used as a reference for NRS-A validation. The other standardized anxiety measuring tools (STAI-T and HADS-A) were also highly reliable.

The results of both measurements carried out in the present study showed a high positive correlation between NRS-A and STAI-S. They suggest a high convergence validity between the NRS-S and STAI-S tools. Although there is little evidence in the literature, the relationship between NRS-A and STAI-S was shown to be stronger than reported by other researchers. This corelation in our study was stronger than that obtained in the group of adult dental patients (rho $=0.6563 ; p<0.05)$ [23], as well as in the group of pediatric patients ( $r$ from 0.424 to 0.639 ) [22]. In the present study, the corelation between NRS-A and STAI-S was stronger than this in studies which also compared other single-item scales, such as VAS-A to STAI-S in patients undergoing surgical procedures $(r=0.555$ to 0.593$)$ [31]. It was also similar or stronger when compared to the corelation measured with VAS-A and STAI-S in three timepoints (at admission to the operation theatre: $r=0.76, p<0.001$; at skin closure: $r=0.60, p<0.001$; two hours after the procedure: $r=0.65, p<0.001$ ) [32] in patients undergoing cesarean section [32]. The strength of the correlation between NRS-A and STAI-T was slightly weaker than the strength of the correlation between STAI-T and STAI-S, and slightly stronger than the correlation between NRS-A and STAI-T ( $r=0.3456$, $p<0.05$ ) obtained the study by Walawender et al. [23]. Positive correlations between NRS-A and HADS-A of a similar strength as between STAI-S and HADS-A were obtained. The above results enable NRS-A to be considered as a relevant tool for measuring state anxiety in Polish postpartum females. 


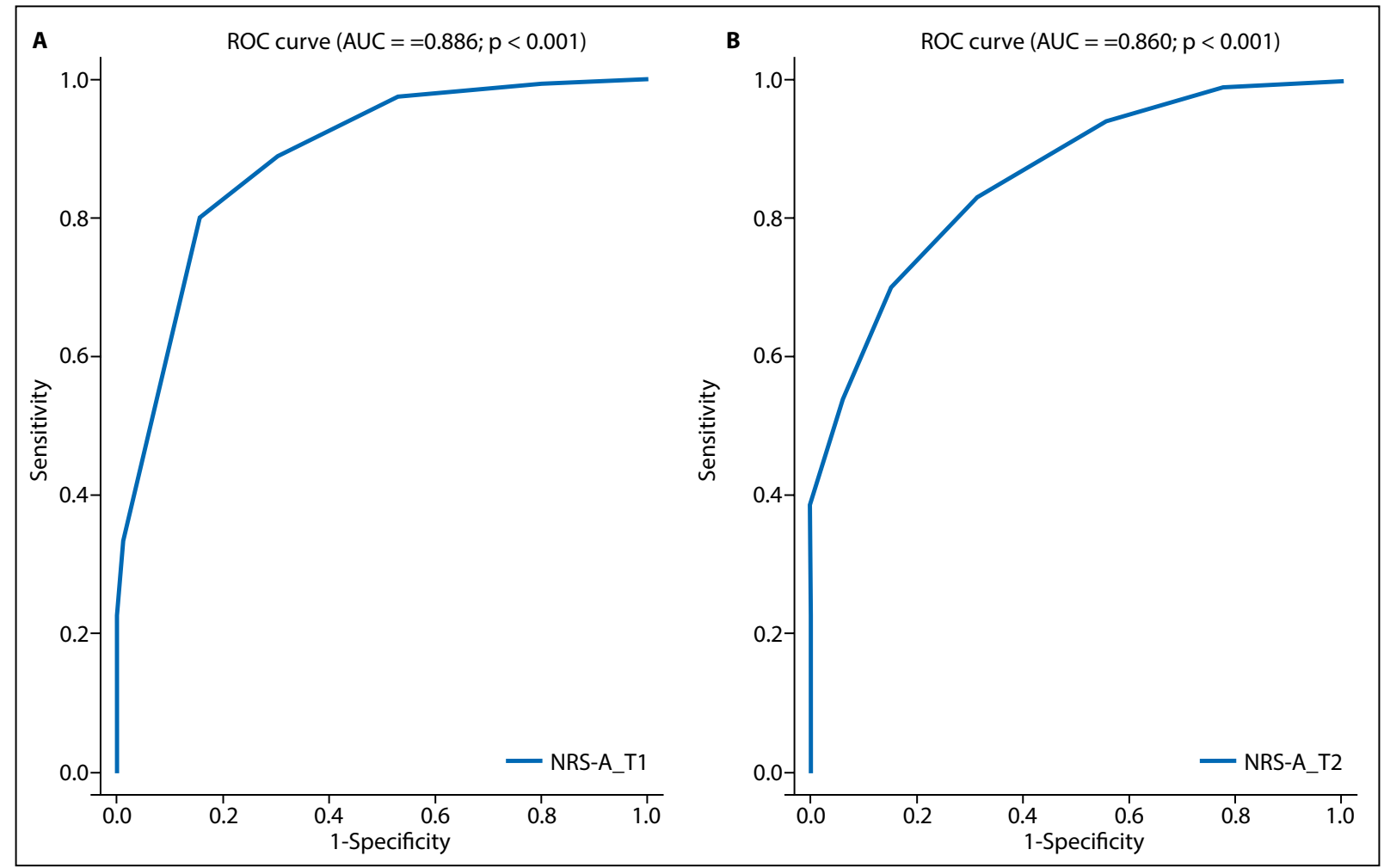

Figure 2. ROC curves; A. ROC curve calculated for NRS-A_T1 using STAI-S_T1 where a score of more than 40 was selected as an indicator of high anxiety. A NRS-A cut-off value of 3.5/10 reflected the best combination of sensitivity ( $80 \%)$ and specificity ( $84 \%)$; B. ROC curve calculated for NRS-A_T2 using STAI-S_T2 where a score of more than 40 was selected as an indicator of high anxiety. A NRS-A cut-off value of 3.5/10 reflected the best combination of sensitivity ( $80 \%)$ and specificity ( $85 \%)$

The absolute stability values for state anxiety measured using STAI-S in two measurements with an interval of 3-4 weeks for women and men of different ages range from 0.39 to 0.81 . In the group of 25 Polish women aged 21-40, the absolute stability is $r=0.59$ [20]. Obtaining a similar high strength of dependent measurements (using the absolute stability method with the retest test) of state anxiety between the first day and the second day on both scales (NRS-A - rho $=0.708$ and STAI-S - rho $=0.701)$, as well as obtaining a lack of differences in the anxiety level measured on both scales, allows NRS-A to be considered as a reliable tool.

No studies concerning the determination of the cut-off point were found for patients with high anxiety on NRS-A. The present research filled this gap. The cut-off points for separating patients with high anxiety using STAI-S equal to 40 was selected according to the recommendation of the manual for the Polish version of STAI-S for the group of women in the age range of 21-40. This is similar to the age of the studied population in the author's previous study [20], and also similar to the studies that validate the single visual analogue scale for anxiety (VAS-A) from 0 to 100 [31, 33].

The obtained (on the basis of the ROC curve analysis) cut-off point of 3.5/10 on NRS-A is similar to the values ob- tained by Labaste et al. on VAS-A with a shift of one decimal place (34/100) [31], and lower than the values obtained by Facco et al. (46/100) [33]. Measurements were conducted at two points (using the test-retest method). In both measurements, the values of the cut-off point coincided with each other. The range for high anxiety on NRS-A should therefore be 4 and above (considering that the STAI-S cut-off point is equal to 40). However, it should be noted that in the group of 90 women, which is a group that normalizes the sten in the Polish STAI adaptation for 21-40 years old, the mean state anxiety was 36.80 (the median was not given), i.e. it considered the group of patients without high anxiety [20]. In the author's study, for 200 women after childbirth, the median of anxiety in the first day was 42.5 , and in the second day was 42 . Both medians are in the high anxiety group. For this reason, the value of 3.5/10 on NRS-A for identifying patients with high anxiety should be treated as a starting point for further research concerning the identification of high anxiety in women during the puerperium.

Additional evidence of the reliability of the measurement using NRS-A in relation to STAI-S is the comparability of the similar values of the AUC, sensitivity and specificity of both ROC curve models for the thresholds that indicate the risk of an anxiety disorder in patients (defined by 


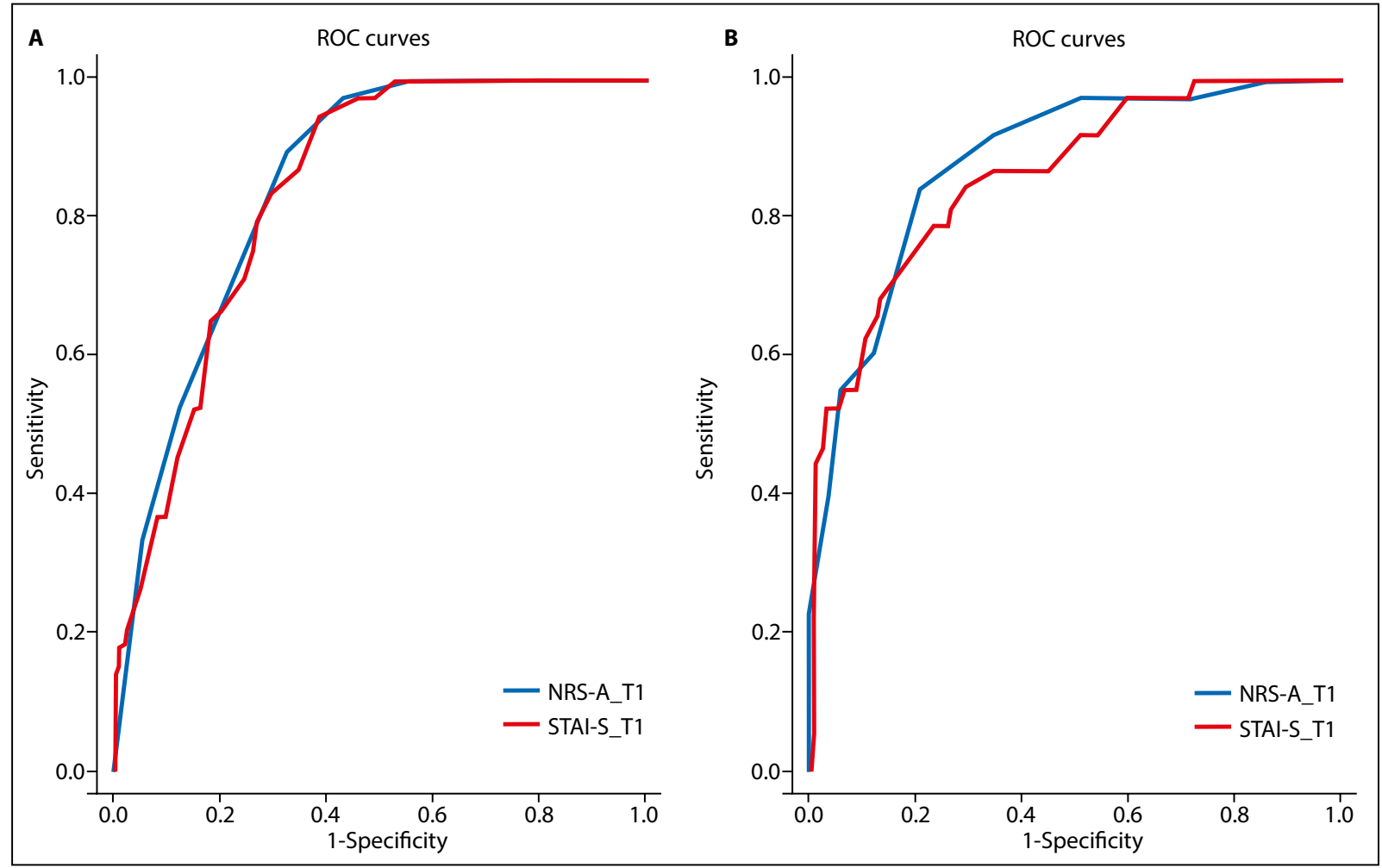

Figure 3. ROC curves; A. Calculated for NRS-A_T1 (AUC $=0.852 ; p<0.001$ ) and for STAI-S_T1 (AUC $=0.842 ; p<0.001$ ) using HADS-A, where a score of more than 10 was selected as an indicator of anxiety disorders. A NRS-A cut-off value of $4.5 / 10$ reflected the best combination of sensitivity (89\%) and specificity (69\%). A STAI-S cut-off value of $42.5 / 80$ reflected the best combination of sensitivity (95\%) and specificity (62\%);

B. Calculated for NRS-A_T2 (AUC $=0.880 ; p<0.001$ ) and for STAI-S_T2 (AUC $=0.863 ; p<0.001$ ) using HADS-A, where a score of more than 10 was selected as an indicator of anxiety disorders. A NRS-A cut-off value of $4.5 / 10$ reflected the best combination of sensitivity (84\%) and specificity (79\%). A STAI-S cut-off value of 50.5/80 reflected the best combination of sensitivity (71\%) and specificity (85\%)

Table 5. Anxiety (measured using NRS-A and STAI-S) in the group of patients declaring no need for emotional support (NES1) vs the group of patients declaring a need for emotional support (NES2) on the first (T1) and the second (T2) day

\begin{tabular}{|c|c|c|c|c|c|c|}
\hline & Mdn & Mrang & Mdn & Mrang & $Z(U)$ & $\mathbf{p}$ \\
\hline & \multicolumn{2}{|c|}{ NES1_T1 ( $n=99)$} & \multicolumn{2}{|c|}{ NES2_T1 $(n=101)$} & & \\
\hline NRS-A_T1 & 2 & 75.21 & 5 & 125.29 & -6.155 & $<0.001$ \\
\hline \multirow[t]{2}{*}{ STAI-S_T1 } & 37 & 72.66 & 49 & 127.79 & -6.739 & $<0.001$ \\
\hline & \multicolumn{2}{|c|}{ NES1_T2 $(n=104)$} & \multicolumn{2}{|c|}{ NES2_T1 $(n=96)$} & & \\
\hline NRS-A_T2 & 2 & 75.43 & 4.5 & 127.66 & -6.422 & $<0.001$ \\
\hline STAI-S_T2 & 37 & 77.46 & 46.5 & 125.46 & -5.863 & $<0.001$ \\
\hline
\end{tabular}

Mdn — median; NRS-A — Numerical Rating Scale for Anxiety; STAI-S — State and Trait Anxiety Inventory-State Anxiety

the reference cut-off point on HADS-A equal to 10). Marking the cut-off point on a straight line using the NRS-S scale allows for the quick identification of patients with a high level of anxiety during the puerperium.

The innovative implementation of dividing patients in the author's study into those reporting a need for emotional support or those reporting a lack of such a need made it possible to assess the levels of anxiety in these groups on both scales (NRS-A and STAI-S). Similar results of the Mann-Whitney
U test on both scales confirmed a significant difference in the levels of anxiety in both groups. In the group of patients reporting a need for emotional support in both measurements, the mean level of anxiety was above the cut-off point for patients with high anxiety in the case of both tools (over 3.5 on NRS-A and over 40 on STAI-S). In turn, in the group of patients reporting no need for emotional support in both measurements, the average level of anxiety was below the cut-off point for patients with high anxiety in the case of both tools. 
The ability to measure anxiety in a simple way allows for a quick preliminary qualification of patients for emergency interventions. Considering both days of puerperium, the need for emotional support was declared by nearly half of the patients. The NICE guidelines[17] recommend the monitoring of the emotional state of women in the perinatal period and the use of evidence-based relief interventions. The NRS-A scale, tested in terms of its accuracy and reliability, may facilitate the assessment of puerperal anxiety. An additional advantage of NRS-A is its free availability and its similarity to the well-known NRS for assessing pain, which is recommended for use in hospitals [12, 34]. It takes a few seconds for the respondent to provide a one value for anxiety experienced at a given moment [22]. Taking into account the period of early puerperium, in which postpartum females may feel discomfort caused by pain and in which they also have a limited time to fill in time-consuming questionnaires (due to the need of caring for their newborn), NRS-A gives the opportunity to assess anxiety in a simple, quick, accurate and honest way.

The limitation of the study is the fact that patients from only one clinical centre were examined, and that the evaluated population was homogenic in terms of the patients' health, education and economic situation, as well as the health of their children.

\section{CONCLUSIONS}

The present study showed that NRS-A is a valid and reliable tool for measuring anxiety in postpartum females. Routine anxiety measurements with a numerical single-item postpartum scale can be used to identify patients with high anxiety in order to provide emotional support to patients in early postpartum.

\section{Conflict of interest}

All authors declare no conflict of interest.

\section{REFERENCES}

1. Ross LE, McLean LM. Anxiety disorders during pregnancy and the postpartum period: A systematic review. J Clin Psychiatry. 2006; 67(8): 1285-1298, doi: 10.4088/jcp.v67n0818, indexed in Pubmed: 16965210.

2. House SJ, Tripathi SP, Knight BT, et al. Obsessive-compulsive disorder in pregnancy and the postpartum period: course of illness and obstetrical outcome. Arch Womens Ment Health. 2016; 19(1): 3-10, doi: 10.1007/s00737-015-0542-z, indexed in Pubmed: 26173597.

3. Grekin R, O'Hara MW. Prevalence and risk factors of postpartum posttraumatic stress disorder: a meta-analysis. Clin Psychol Rev. 2014; 34(5): 389-401, doi: 10.1016/j.cpr.2014.05.003, indexed in Pubmed: 24952134.

4. Schobinger E, Stuijfzand S, Horsch A. Acute and post-traumatic stress disorder symptoms in mothers and fathers following childbirth: a prospective cohort study. Front Psychiatry. 2020; 11: 562054, doi: 10.3389/fpsyt.2020.562054, indexed in Pubmed: 33414729.

5. Agbaje OS, Anyanwu Jl, Umoke PIC, et al. Depressive and anxiety symptoms and associated factors among postnatal women in Enugu-North Senatorial District, South-East Nigeria: a cross-sectional study. Arch Public Health. 2019; 77: 1, doi: 10.1186/s13690-018-0329-6, indexed in Pubmed: 30647917.
6. Alipour Z, Lamyian M, Hajizadeh E. Anxiety and fear of childbirth as predictors of postnatal depression in nulliparous women. Women Birth. 2012; 25(3): e37-e43, doi: 10.1016/j.wombi.2011.09.002, indexed in Pubmed: 21959041.

7. Wisner KL, Sit DKY, McShea MC, et al. Onset timing, thoughts of self-harm, and diagnoses in postpartum women with screen-positive depression findings. JAMA Psychiatry. 2013; 70(5): 490-498, doi: 10.1001/jamapsychiatry.2013.87, indexed in Pubmed: 23487258.

8. Giardinelli L, Innocenti A, Benni L, et al. Depression and anxiety in perinatal period: prevalence and risk factors in an Italian sample. Arch Womens Ment Health. 2012; 15(1): 21-30, doi: 10.1007/s00737011-0249-8, indexed in Pubmed: 22205237.

9. Accortt $E E$, Wong MS. It is time for routine screening for perinatal mood and anxiety disorders in obstetrics and gynecology settings. Obstet Gynecol Surv. 2017; 72(9): 553-568, doi: 10.1097/OGX.0000000000000477, indexed in Pubmed: 28905985.

10. Ahmed A, Bowen A, Feng CX, et al. Trajectories of maternal depressive and anxiety symptoms from pregnancy to five years postpartum and their prenatal predictors. BMC Pregnancy Childbirth. 2019; 19(1):26, doi: 10.1186/s12884-019-2177-y, indexed in Pubmed: 30642277.

11. Rozporządzenie Ministra Zdrowia z dnia 16 sierpnia 2018 r. w sprawie standardu organizacyjnego opieki okołoporodowej (Dz.U. 2018 poz. 1756).

12. Borges Nd, Pereira LV, de Moura LA, et al. Predictors for moderate to severe acute postoperative pain after cesarean section. Pain Res Manag. 2016; 2016: 5783817, doi: 10.1155/2016/5783817, indexed in Pubmed: 27956847 .

13. Gamez $\mathrm{BH}$, Habib AS. Predicting severity of acute pain after cesarean delivery: a narrative review. Anesth Analg. 2018; 126(5): 1606-1614, doi: 10.1213/ANE.0000000000002658, indexed in Pubmed: 29210789.

14. Gorkem U, Togrul C, Sahiner Y, et al. Preoperative anxiety may increase postcesarean delivery pain and analgesic consumption. Minerva Anestesiol. 2016; 82(9): 974-980, indexed in Pubmed: 27028449.

15. Hayes SC, Strosah IKD, Willson KG. Terapia akceptacji i zaangażowania: Proces i praktyka uważnej zmiany. Wydawnictwo Uniwersytetu Jagiellońskiego, Kraków 2013.

16. Silverwood V, Nash A, Chew-Graham CA, et al. Healthcare professionals' perspectives on identifying and managing perinatal anxiety: a qualitative study. Br J Gen Pract. 2019; 69(688): e768-e776, doi: 10.3399/bjgp19X706025, indexed in Pubmed: 31548296.

17. National Institute for Health and Care Excellence. Principles of care in pregnancy and the postnatal period. In: Antenatal and postnatal mental health: clinical management and service guidance. 2014

18. Julian LJ. Measures of anxiety: State-Trait Anxiety Inventory (STAI), Beck Anxiety Inventory (BAI), and Hospital Anxiety and Depression Scale-Anxiety (HADS-A). Arthritis Care Res (Hoboken). 2011; 63 Suppl 11: S467-S472, doi: 10.1002/acr.20561, indexed in Pubmed: 22588767.

19. Guillén-Riquelme A, Buela-Casal G. [Meta-analysis of group comparison and meta-analysis of reliability generalization of the State-Trait Anxiety Inventory Questionnaire (STAI)]. Rev Esp Salud Publica. 2014; 88(1): 101-112, doi: 10.4321/S1135-57272014000100007, indexed in Pubmed: 24728394.

20. Wrześniewski K, Sosnowski T, Jaworska A et al., [State-Trait Anxiety Inventory. Polish adaptation of STAI], Warszawa: Pracownia Testów Psychologicznych, 2006.

21. Karcioglu O, Topacoglu H, Dikme O, et al. A systematic review of the pain scales in adults: Which to use? Am J Emerg Med. 2018; 36(4): 707-714, doi: 10.1016/j.ajem.2018.01.008, indexed in Pubmed: 2932111.

22. Crandall $M$, Lammers $C$, Senders $C$, et al. Initial validation of a numeric zero to ten scale to measure children's state anxiety. Anesth Analg. 2007; 105(5): 1250-1253, doi: 10.1213/01.ane.0000284700.59088.8b, indexed in Pubmed: 17959951.

23. Walawender I, Roczniak W, Nowak D, et al. Applicability of the Numeric Scale for Anxiety Evaluation in Patients Undergoing Dental Treatment. Dent Med Probl. 2015; 52(2): 205-214.

24. Spielberger C, Gorsuch R, Lushene R. Manual for the State-Trait Anxiety Inventory (Form Y1 - Y2). CA:Consulting Psychologists Press 1983.

25. Zigmond AS, Snaith RP. The hospital anxiety and depression scale. Acta Psychiatr Scand. 1983; 67(6): 361-370, doi: 10.1111/j.1600-0447.1983. tb09716.x, indexed in Pubmed: 6880820.

26. Majkowicz M. Praktyczna ocena efektywności opieki paliatywnej - wybrane 133 techniki badawcze. In: de Walden-Gałuszko K, Majkowicz M. ed. Ocena jakości opieki paliatywnej w teorii i praktyce. Akademia Medyczna w Gdańsku, Gdańsk 2000: 21-42. 
27. Davey HM, Barratt AL, Butow PN, et al. A one-item question with a Likert or Visual Analog Scale adequately measured current anxiety. J Clin Epidemiol. 2007; 60(4): 356-360, doi: 10.1016/j.jclinepi.2006.07.015, indexed in Pubmed: 17346609.

28. Gustafson LW, Gabel P, Hammer A, et al.Validity and reliability of State-Trait Anxiety Inventory in Danish women aged 45 years and older with abnormal cervical screening results. BMC Med Res Methodol. 2020; 20(1): 89, doi: 10.1186/s12874-020-00982-4, indexed in Pubmed: 32326886.

29. Delgado AM, Freire Ad, Wanderley EL, et al. Analysis of the construct validity and internal consistency of the State-Trait Anxiety Inventory (STAI) State-Anxiety (S-Anxiety) Scale for Pregnant Women during Labor. Rev Bras Ginecol Obstet. 2016; 38(11): 531-537, doi: 10.1055/s-00361593894, indexed in Pubmed: 27813038.

30. Quek KF, Low WY, Razack AH, et al. Reliability and validity of the Spielberger State-Trait Anxiety Inventory (STAI) among urological patients: a Malaysian study. Med J Malaysia. 2004; 59(2): 258-267, indexed in Pubmed: 15559178.
31. Labaste $F$, Ferré $F$, Combelles $\mathrm{H}$, et al. Validation of a visual analogue scale for the evaluation of the postoperative anxiety: A prospective observational study. Nurs Open. 2019; 6(4): 1323-1330, doi: 10.1002/nop2.330, indexed in Pubmed: 31660159.

32. Hepp P, Hagenbeck C, Burghardt B, et al. MAGIC Group. Measuring the course of anxiety in women giving birth by caesarean section: a prospective study. BMC Pregnancy Childbirth. 2016; 16: 113, doi: 10.1186/s12884-016-0906-z, indexed in Pubmed: 27188222.

33. Facco E, Stellini E, Bacci C, et al. Validation of visual analogue scale for anxiety (VAS-A) in preanesthesia evaluation. Minerva Anestesiol. 2013; 79(12): 1389-1395, indexed in Pubmed: 23860442.

34. Castarlenas $\mathrm{E}$, Jensen MP, von Baeyer $\mathrm{CL}$, et al. Psychometric properties of the numerical rating scale to assess self-reported pain intensity in children and adolescents: a systematic review. Clin J Pain. 2017; 33(4): 376-383, doi: 10.1097/AJP.0000000000000406, indexed in Pubmed: 27518484 . 